\title{
Aeration effect on bacteria morphology contained in Bioactivators for household waste water treatment
}

\author{
O.G. Selivanov ${ }^{1}$, A.A. Skop ${ }^{2}$, E.S. Pikalov ${ }^{3}$, A.S. Kolosova ${ }^{4}$ \\ ${ }^{1}$ Vladimir State University named after A. G. and N. G. Stoletovs, Vladimir, Russian Federation \\ selivanov6003@mail.ru \\ ${ }^{2}$ Vladimir State University named after A. G. and N. G. Stoletovs, Vladimir, Russian Federation, \\ alexahabib@yandex.ru \\ ${ }^{3}$ Vladimir State University named after A. G. and N. G. Stoletovs, Vladimir, Russian Federation \\ evgeniy-pikalov@mail.ru \\ ${ }^{4}$ Vladimir State University named after A. G. and N. G. Stoletovs, Vladimir, Russian Federation, \\ anastasiya_kolosova_777@mail.ru
}

\begin{abstract}
The paper presents the research results on the aeration effect on bacteria morphology contained in three bioactivators available at the local market, and the dependence of their efficiency on the occurring morphological changes. Aeration for obligate aerobes was found to cause either bacterial cells size increase, which in turn increases the amount of the consumed organic pollutants, or their length decrease due to the reduction of the cell division period, which improves the bacteria survival in wastewater containing toxic substances. Both variants of the changes provide bioactivators efficiency improvement. It has also been detected that the combination of obligate aerobes and facultative anaerobes allows achieving the highest treatment efficiency of domestic wastewater even containing toxic substances.
\end{abstract}

Key words:household waste water, organic pollutants, biological treatment, bioactivators, aerobic microorganisms, aeration

\section{INTRODUCTION}

Annually the industrial and household water consumption and housing increases, inevitably causing the increase of waste water amount, which is contaminated by a variety of substances contained in water in different states and concentrations. Therefore various methods and technologies must be used for wastewater treatment, which allow removing specific types of pollutants from water [14].

The main pollutants of domestic wastewater are organic substances and compounds, such as fats, proteins, carbohydrates, fiber, alcohols, organic acids, etc. These pollutants are found in water as suspended or dissolved particles. Biological treatment, based on the ability of certain microorganisms to use organic and some inorganic (hydrogen sulfide, sulfides, ammonia, nitrites) impurities for their vital activity, is known to be the most effective method for wastewater treatment from organic impurities. Depending on the micro-organisms type, biological purification is distinguished as aerobic and anaerobic. In aerobic conditions, in contrast to anaerobic, the treatment is carried out with bacteria, whose vital activity requires oxygen $[5,6]$.

In addition to organic pollutants and oxygen, bacteria activity is affected by temperature, water $\mathrm{pH}$, wastewater flow turbulence, as well as biogenic elements (primarily $\mathrm{N}$, $\mathrm{P}$ and $\mathrm{K}$ ) and substances that can produce toxic effect on bacteria.

Thus, to ensure the biological treatment efficiency it is necessary to provide optimal conditions for bacteria activity, where they will actively develop and use organic pollutants for their nutrition. Herewith it is rational to select bacteria which are most resistant to foreign substances, such as synthetic detergents, and fluctuations in parameters such as oxygen, temperature and media $\mathrm{pH}$.

Special additives - bioactivators containing both aerobic and anaerobic microorganisms possessing broad adaptive capabilities are widely used to intensify biological treatment in autonomous sewer systems using septic tanks. The bioactivators increase the decomposition speed of organic pollutants and allow improving the rate of domestic waste water treatment, which is especially important in places where centralized treatment facilities are not available in the conditions especially in cottage areas, which have been widely developing recently. To intensify the growth the microorganisms population and the processes of biological wastewater treatment, the methods of nutrients additional introduction into the water or joint introduction of microorganisms and nutrients as a part of bioactivators are widely used [7-9].

The research authors have previously experimented to study the efficiency dependence of the three bioactivators available in the local market on aeration and the presence of synthetic detergents in wastewater. It has been found that bacteria contained in the studied bioactivators are aerobic and gram-positive, and the bioactivators effectiveness increases with the aeration by an average of 8-15\% and decreases when synthetic detergents are present in the waste water $[10,11]$.

The research objective was to study the aeration effect on bacteria morphology contained in the previously studied bioactivators, to assess the relationship between morphological changes and domestic wastewater treatment efficiency. 


\section{RESEARCH OBJECTS AND METHODS}

To study the morphology and to evaluate the bioactivator microorganisms efficiency for the household waste water treatment containing organic pollutants, three bioactivators have been selected: "Doctor Robic" 109 (USA)," Biobac " BB-YS 060 (Russia) and "Sanex " (Russia).

To study the morphology, suspensions were prepared from the studied bioactivators in distilled water with the concentration of $0.1 \mathrm{~g} / \mathrm{l}$. Two suspensions were prepared for each bioactivator: one was subjected to aeration using air oxygen supplied by compressor with a capacity of 0.12 $\mathrm{m} 3 / \mathrm{h}$. Suspensions of bioactivators were kept in static conditions for four days at an ambient temperature of $22 \pm$ $2{ }^{\circ} \mathrm{C}$.

Then molten agarized medium from meat-peptone agar was prepared and poured into 20-30 ml Petri dishes. After the medium solidification, bioactivator suspensions surface smears were made using sterile inoculation loop. Smears were zigzags on the surface (streak). Petri dishes with smears were also kept under static conditions in thermostat for two days at the temperature of $30^{\circ} \mathrm{C}$.

After the smears incubation period, samples were prepared, which were colored by the Gram method and studied by light microscopy with an immersion system (lens x 100) on Micros MC-20 microscope (Austria).

To study the treatment efficiency, the previous studies results with the model solutions have been used. To prepare the model solutions, starch GOST 53876-2010, sucrose brand "p.f.a." GOST 5833-75 and whole milk powder GOST 33629-2015 were mixed, taken in equal quantities of the total concentration of $5.1 \mathrm{~g} / \mathrm{l}$. Model solutions for each bioactivator were prepared in batches of four solutions each, two of which were aerated. Synthetic detergent (SD) "Fairy" for dishwashing, which played the role of toxicant for microorganisms, was introduced into one of the model solutions without aeration. SD was also introduced into one of the aerated model solutions. To assess treatment efficiency and relation between treatment efficiency and morphological changes, we took the values for COD reducing on the twelfth day relative to the initial values $[10,11]$.

\section{RESEARCH RESULTS AND DISCUSSION}

The microscopy results of bacterial associations obtained at studying bacteria morphology from suspensions samples of "Doctor Robic" bioactivator without aeration are shown in figure 1 . The resulted data shows that the bacteria species, contained in "Doctor Robic" bioactivator, belong to the Bacillus (Bacillus) genus and are long and thin rod-shaped cells. Most bacteria in this case are characterized by the formation of large associations of irregular shape.

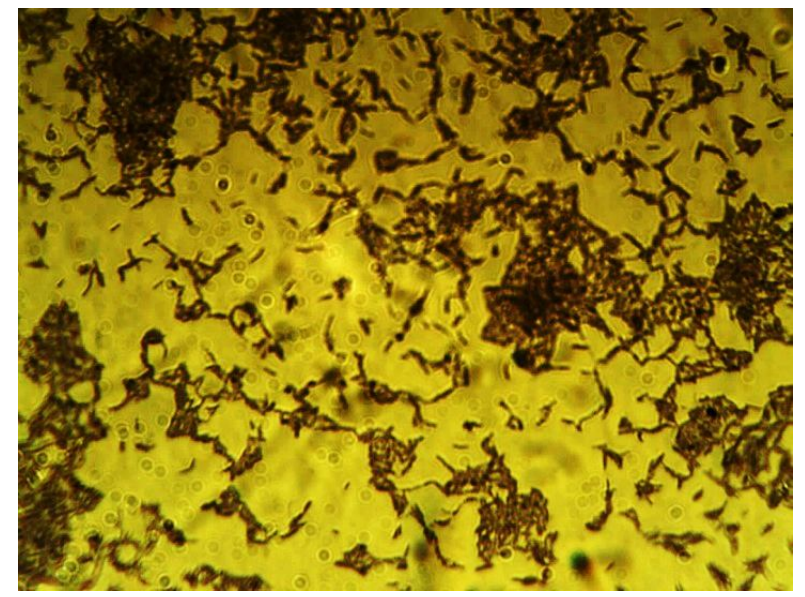

Figure 1: Microscopy results of bacterial associations of "Doctor Robic" study without aeration

The microscopy results of the microbial associations obtained when studying the bacteria morphology from the aerated suspensions samples of "Doctor Robic" bioactivator are shown in figure 2 . The received data proved that bacteria species composition remains after aeration, but the length and diameter of rod-shaped cells decreases, and the associations become less enlarged.

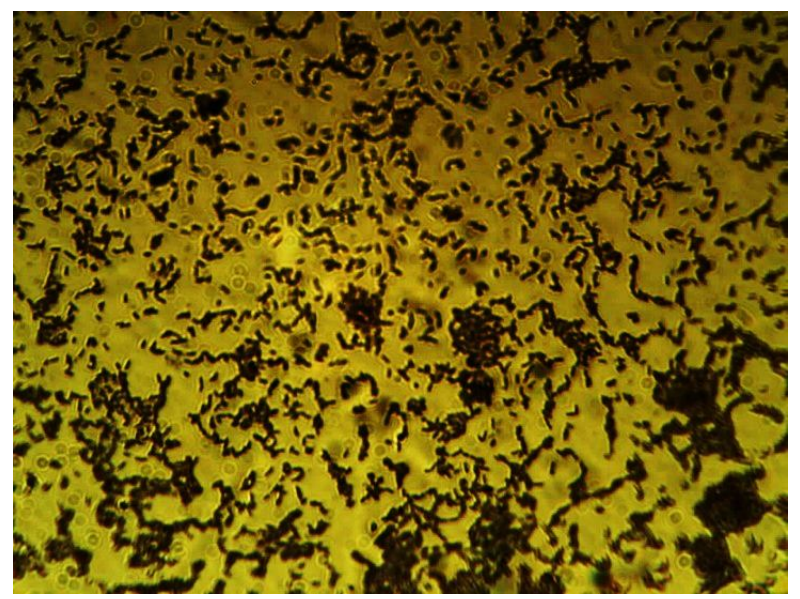

Figure 2: Microscopy results of bacterial associations of "Doctor Robic" bioactivator with aeration

It can be assumed that aeration results in creating favorable conditions for these bacteria causing the increase of the bacterial cells diameter and their active reproduction thanks to the reduction of the cell division period, when they do not have enough time to grow larger. Due to the bacteria size reduction, the size of bacterial associations also decreases, and bacteria tend to form new associations, rather than to enlarge the existing ones.

The microscopy results of microbial associations, obtained during the study of bacteria morphology from suspensions samples of "Biobac" bioactivator without aeration, are shown in figure 3 . 


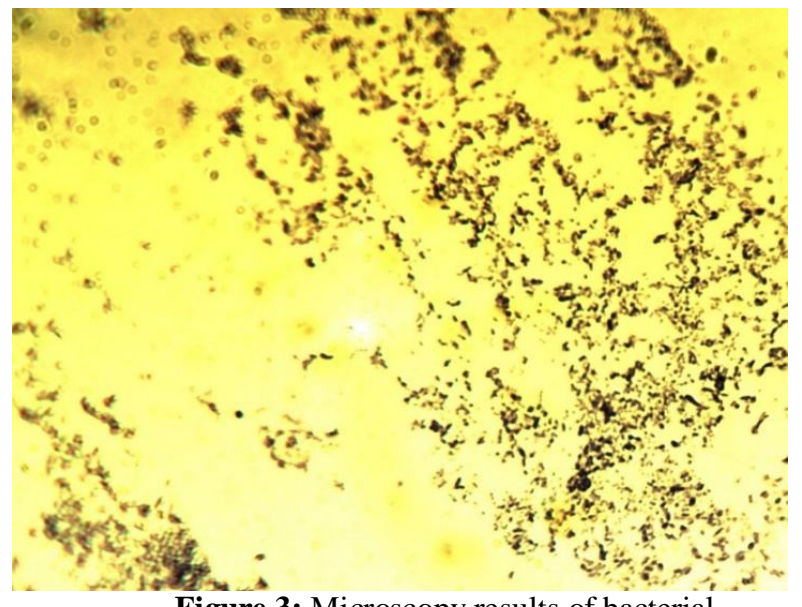

Figure 3: Microscopy results of bacterial

associations of "Biobac" bioactivator without aeration

The resulted data proves that bacteria species composition in the "Biobac" bioactivator includes two varieties:

- Bacillus (Bacillus) genus which are rod-shaped bacteria, smaller in size in comparison with the bacilli contained in the bioactivator "Doctor Robic»;

- Cocci (Coccaceae) genus, which are small spherical cells.

Herewith bacteria are characterized by the small size associations of a small number of bacteria in them.

The microscopy results of microbial associations obtained during the study bacteria morphology from the aerated suspensions samples of "Biobac" bioactivator are shown in figure 4.

As the received data proves aeration provides sharp increase in bacilli number, which cells are significantly larger in diameter and length compared to bacilli from the smear obtained from a suspension without aeration. At the same time aeration causes cocci transition to a sporogenous state, and the spores are not colored. Herewith the tendency to forming a large number of small associations with a small number of bacteria in them remains.

Bacilli from "Biobac" bioactivator are assumed to refer to the aerobic bacteria growing quickly and reproducing in oxygen, but cocci from this bioactivator refer to anaerobic bacteria that are not able to adapt to oxygen.

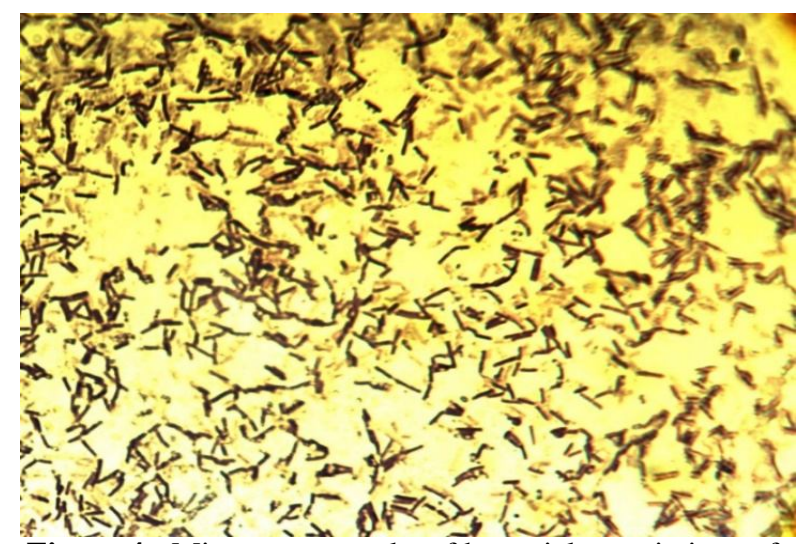

Figure 4: Microscopy results of bacterial associations of "Biobac" bioactivator with aeration
The microscopy results of microbial associations obtained during the study of bacteria morphology in "Sanex" suspensions without aeration are shown in figure 5.

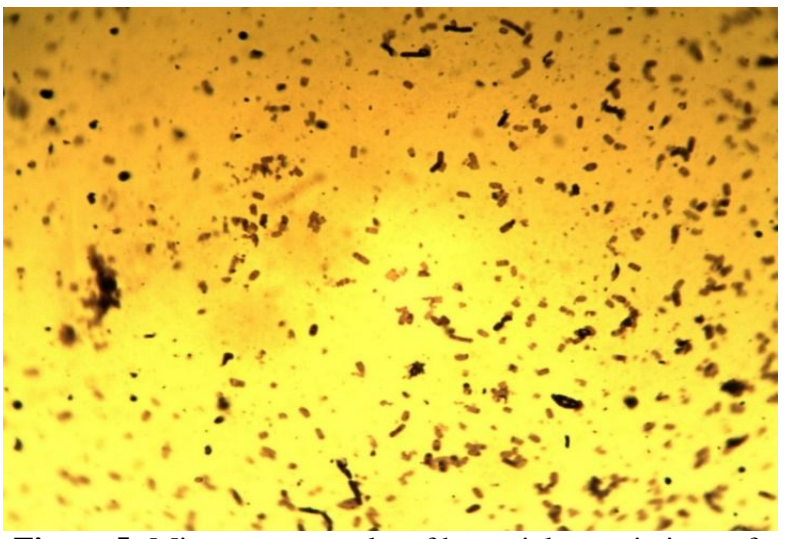

Figure 5: Microscopy results of bacterial associations of "Sanex" bioactivator without aeration

The received data revealed that bacteria species composition contained in "Sanex" bioactivator includes two varieties:

- Bacillus (Bacillus) genus, which are rod-shaped bacteria whose cells differ in large diameter and length in comparison to the bacilli contained in "Doctor Robic" and "Biobac» bioactivators;

- Cocci (Coccaceae) genus, which are spherical cells of various sizes.

Herewith Cactaceae genus bacteria quantitatively prevail over Bacillus bacteria in this bioactivator. In this case bacterial associations are characterized by the smallest size and number of cells in comparison with the two previously considered bioactivators.

The microscopy results of microbial associations obtained during the bacteria morphology study of the suspensions samples from "Sanex" bioactivator with aeration are shown in figure 6.

The received data confirms that bacteria species composition remains with aeration, but the length of rodshaped cells decreases while maintaining their diameter. Herewith the number of cocci remains approximately at the same level and their number still exceeds the number of bacilli. Bacterial associations increase in size by increasing the number of bacteria in them.

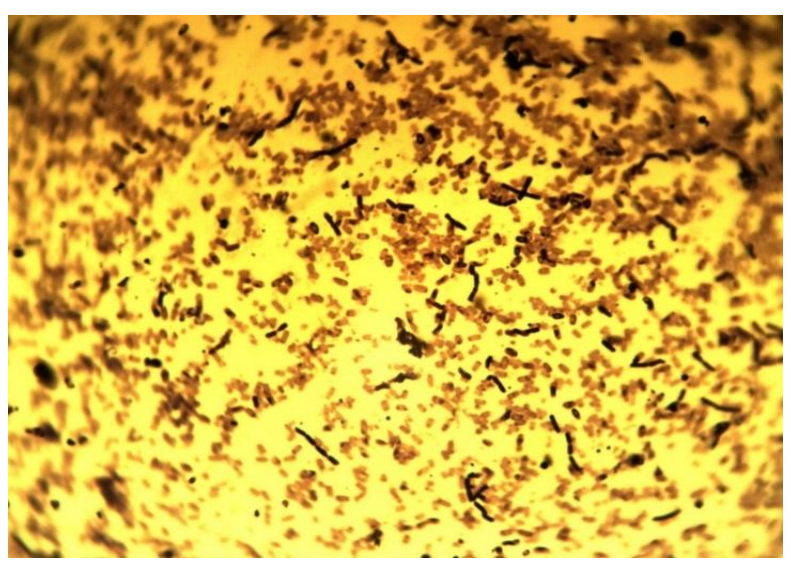

Figure 6: Microscopy results of bacterial associations of "Sanex" bioactivator with aeration 
As in the case with "Doctor Robic" bioactivator, it can be assumed that aeration stipulates faster division of rodshaped cells, so they do not have enough time to grow large.

Thus, In aerated conditions the rod-shaped cells in all the studied bioactivators are characterized by the number increase alongside one of the two morphological changes: length decrease due to the reduction of the cell division period, or size increase (both diameter and length) thanks to the created favourable aerobic conditions. The spherical cells morphology is poorly affected by aeration: for bacteria in "Biobac" bioactivator, cocci transition to a spore-like state is observed, and for bacteria in "Sanex", cocci activity is observed without any visible morphological changes. For most bacteria associations the size is decreased resulted by aeration, due to the bacteria size decrease alongside the increase in the total number of associations on the samples studied area.

The purification efficiency index received in the previous experiments for reducing COD of the model solutions for different bioactivators introduced into the model solutions and maintained under different conditions are shown in table $[10,11]$.

Table: Treatment efficiency of model solutions under various conditions

\begin{tabular}{|l|c|c|c|c|}
\hline \multirow{3}{*}{ Bioactivator } & \multicolumn{3}{|c|}{ Treatment efficiency, \% } \\
\cline { 2 - 5 } & \multicolumn{2}{|c|}{ aeration } & \multicolumn{2}{c|}{ no aeration } \\
\cline { 2 - 5 } & without & with & without & with \\
& SD & SD & SD & SD \\
\hline «Doctor Robic» & 90.8 & 50.5 & 95.6 & 64.0 \\
\hline «Biobac» & 69.0 & 64.4 & 77.8 & 71.0 \\
\hline «Sanex» & 54.7 & 48.8 & 71.1 & 79.2 \\
\hline
\end{tabular}

When comparing the data concerning morphological changes and treatment efficiency, it can be concluded that the rod-shaped cells enlargement, observed during aeration for "Biobac" bioactivator, allows for the greater efficiency increase $(8.8 \%)$ than the reduction of the cell division period observed during aeration Doctor Robicbioactivator (4.8 \%). However, "Doctor Robic" bioactivator is characterized by higher efficiency increase at model solutions aeration containing SD than "Biobac" (13.5 and $6.6 \%$, respectively). Consequently, cell enlargement facilitates increases the amount of substances consumed by bacteria, but shortening cell division period increases the bacteria survival in SD media. The predominant cocci number in "Sanex" bioactivator, which morphology is practically unaffect by aeration, and bacilli, which cell division period is reduced by aeration alongside their size decrease, allow for achieving the greatest increase of treatment efficiency during aeration of model solutions containing and not containing SD (16.4 and 30.4\%, respectively).

\section{CONCLUSIONS}

The research results stated that aeration affects morphology bacilli and practically does not affect the cocci morphology contained in the studied bioactivators. Herewith all the detected bacilli clearly belong to obligate aerobes and are developing more actively during aeration, but the detected cocci either belong to the obligate anaerobes and transit into the sporogenous state as a result of aeration, or retain their activity at the same level, i.e. they can be conditionally attributed to facultative anaerobes.

Aeration was revealed to affect the detected rod-shaped bacteria, causing either their size increase, allowing them to increase the amount of consumed organic substances, or to the reduction in the cell division period with the cell size decrease, which increases their survival in toxic substances media while maintaining a high level of purification. The most universal was the bioactivator, containing alongside the rod-shaped bacteria, characterized by the size and cell division period decrease, spherical bacteria, whose morphology is not affected by aeration.

Thus, aeration causes bacteria morphological changes increasing their activity, viability and intensity of organic pollutants treatment in all the studied bioactivators. The choice of a specific bioactivator will depend on the substances in wastewater which are toxic to bacteria. If there no toxicants bioactivators, containing bacteria increases in size with aeration, will be more effective, and if there toxic substances, bioactivators where aeration reduces the cell division period with the cell size decrease will be more effective.

\section{REFERENCES}

1. N.B. Singh, G. Nagpal, S. Agrawal, Rachna"Water purification by using Adsorbents: A Review.'Environmental Technology \& Innovation. 2018, Vol. 11, pp. 187-240.

https://doi.org/10.1016/j.eti.2018.05.006

2. V.Yu. Chukhlanov, O.G. Selivanov, E.S. Pikalov, S.M. Chesnokova, A.A. Podolets"Purification of waterfrom fluoride ions by a lanthanum-containing ceramic material.'Ecology and Industry of Russia. 2018, Vol. 22, № 8, pp. 28-31.

3. O.G. Selivanov, E.S. Pikalov, A.S. Kolosova"Ceramic material for fluoride and phosphate ions removal from natural water.'International Journal of Emerging Trends in Engineering Research. 2020, Vol.8, № 5, pp. 1732-1735.

https://doi.org/10.30534/ijeter/2020/39852020

4. H. Shen, X. Chen, D. Zhang, H. Chen"Generation of soluble microbial products by bioactivated carbon filter during drinking water advanced treatment and its influence on spectral characteristics."Science of The Total Environment, 2016, Vol. 569-570, pp.1289-1298.

5. Y.J. Chan, M.F. Chong, C.L. Law D.G. Hassell "A review on anaerobic-aerobic treatment of industrial and municipal wastewater.'Chemical Engineering Journal, 2009. Vol. 155. Iss. 1-2. pp. 1-18.

6. G. Kassab, M. Halalsheh, A. Klapwijk, M. Fayyad. J.B. van Lier "Sequential anaerobic-aerobic treatment for domestic wastewater - A review."Bioresource Technology, 2010. Vol. 101, Iss. 10. pp. 3299-3310.

https://doi.org/10.1016/j.biortech.2009.12.039

7. S. Doni, C. Macci, C. Martinelli, R. Iannelli, P. Brignoli, S. Lampis, M. Andreolli, G. Vallini, G. Masciandaro"Combination of sediment washing and bioactivators as a potential strategy for dredged 
marine sediment recovery." Ecological Engineering. 2018, Vol.125, pp. 26-37.

8. F. Crisafi, M. Genovese, F.Smedile, D.Russo, M.Catalfamo, M.Yakimov, L.Giuliano, R.Denaro"Bioremediation technologies for polluted seawater sampled after an oil-spill in Taranto Gulf (Italy): A comparison of biostimulation, bioaugmentation and use of a washing agent in microcosm studies."Marine Pollution Bulletin, 2016. Vol. 106. Iss. 1-2. pp.119-126.

9. V. Blonskaja, A. Menert, R. Vilu'Use of twostage anaerobic treatment for distillery waste."Advances in Environmental Research, Vol. 7. Iss. 3. pp. 671-678.

10. O.G. Selivanov, E.S. Pikalov, A.S. Kolosova“The assessment of Bioactivators effectiveness used for theHousehold Waste Water Treatment.'International Journal of Emerging Trends in Engineering Research. 2020, Vol.8, № 6, pp. 2446-2449.

https://doi.org/10.30534/ijeter/2020/39862020

11. O.G. Selivanov, A.A. Skop, E.S. Pikalov, A.S. Kolosova"Aeration for increasing the bioactivators efficiency in treating household wastewater containing synthetic detergents.'International Journal of Emerging Trends in Engineering Research. 2020, Vol.8, № 7, pp. 3580-3583.

https://doi.org/10.30534/ijeter/2020/114872020 